\title{
Relationships between land cover and the surface urban heat island: seasonal variability and effects of spatial and thematic resolution of land cover data on predicting land surface temperatures
}

\author{
Weiqi Zhou • Yuguo Qian · Xiaoma Li • \\ Weifeng Li $\cdot$ Lijian Han
}

Received: 29 September 2012/ Accepted: 2 October 2013/Published online: 22 December 2013

(C) Springer Science+Business Media Dordrecht 2013

\begin{abstract}
We investigated the seasonal variability of the relationships between land surface temperature (LST) and land use/land cover (LULC) variables, and how the spatial and thematic resolutions of LULC variables affect these relationships. We derived LST data from Landsat-7 Enhanced Thematic Mapper $(\mathrm{ETM}+)$ images acquired from four different seasons. We used three LULC datasets: (1) $0.6 \mathrm{~m}$ resolution land cover data; (2) $30 \mathrm{~m}$ resolution land cover data (NLCD 2001); and (3) $30 \mathrm{~m}$ resolution Normalized Difference Vegetation Index data derived from the same ETM+ images (though from different bands) used for LST calculation. We developed ten models to evaluate effects of spatial and thematic resolution of LULC data on the observed relationships between LST and LULC variables for each season. We found that the directions of the effects of LULC variables on predicting LST were consistent across seasons, but the magnitude of effects, varied by season, providing the strongest predictive capacity during summer and the weakest during winter. Percent of imperviousness was
\end{abstract}

Electronic supplementary material The online version of this article (doi:10.1007/s10980-013-9950-5) contains supplementary material, which is available to authorized users.

W. Zhou $(\bowtie) \cdot$ Y. Qian $\cdot$ X. Li · W. Li $\cdot$ L. Han

State Key Laboratory of Urban and Regional Ecology,

Research Center for Eco-Environmental Sciences,

Chinese Academy of Sciences, Shuangqinglu 18,

Haidian District, Beijing 100085, China

e-mail:wzhou@rcees.ac.cn the best predictor on LST with relatively consistent explanatory power across seasons, which alone explained approximately $50 \%$ of the total variation in LST in winter, and up to $77.9 \%$ for summer. Vegetation related variables, particularly tree canopy, were good predictor of LST during summer and fall. Vegetation, particularly tree canopy, can significantly reduce LST. The spatial resolution of LULC data appeared not to substantially affect relationships between LST and LULC variables. In contrast, increasing thematic resolution generally enhanced the explanatory power of LULC on LST, but not to a substantial degree.

Keywords Spatial and thematic resolution .

Urban landscape $\cdot$ Land use/land cover .

Impervious surface $\cdot$ Tree canopy $\cdot$ NDVI .

NLCD

\section{Introduction}

Urban heat islands (UHIs) describe the phenomenon that atmospheric and surface temperatures are higher in urban areas than in surrounding rural areas (Oke 1995; Voogt and Oke 2003). The UHI effect may increase water and energy consumption (Akbari et al. 2001; Guhathakurta and Gober 2007), increase the production of ground level ozone (Akbari et al. 2001), and alter biotic communities (White et al. 2002). Excess heat affects the comfort of urban dwellers and 
may contribute to heat wave disasters (Klinenberg 2002; Duneier 2006). The ecological and social consequences of UHIs have attracted great attention from the research community, urban planners, and public health officials.

As stated, UHIs have both air temperature and surface temperature components (Arnfield 2003; Nichol et al. 2009). The air temperature component generally is further divided into the canopy layer heat island and the boundary layer heat island (Arnfield 2003). Although some studies have reported a close relationship and similar spatial patterns between surface and air temperatures (e.g., Nichol 1994, 1996; Ben-Dor and Saaroni 1997; Nichol et al. 2009), the relationship is not consistent (Arnfield 2003). Air temperature UHIs generally are stronger and exhibit greatest spatial variation at night, whereas the largest difference in patterns of surface UHIs usually occurs during the day (Arnfield 2003; Nichol et al. 2009). In the current study we apply remotely sensed estimates of land surface temperature (LST) to improve our understanding of surface UHIs.

The surface UHI relates directly to land surface characteristics (Oke 1995; Quattrochi and Luvall 1999; Voogt and Oke 2003). Surface modifications brought about by urbanization, typically including replacing soil and vegetation with impervious surfaces and urban structures, are recognized as one of the major causes of UHIs (Arnfield 2003; Voogt and Oke 2003), and a considerable amount of research has been conducted to investigate relationships between LST and urban LULC (e.g., Weng et al. 2004; Yuan and Bauer 2007; Buyantuyev and Wu 2010; Zhou et al. 2011). A variety of remotely sensed data has been used to evaluate LST patterns and assess surface UHIs, including advanced very high resolution radiometeter (AVHRR) (Balling and Brazel 1988), moderate resolution imaging spectroradiometer (MODIS) (Pu et al. 2006), Landsat thematic mapper (TM)/enhanced thematic mapper plus (ETM+) (Nichol 1998; Weng et al. 2004), advanced spaceborne thermal emission and reflection radiometer (ASTER) (Pu et al. 2006), and airborne terrestrial applications sensor (ATLAS), among others.

Land use/land cover (LULC) variables used for assessing UHIs include the normalized difference vegetation index (NDVI), a measure of abundance of green biomass (e.g., Jenerette et al. 2007; Yuan and Bauer 2007), vegetation fraction (Weng et al. 2004), grassland, forest, barren land, water, low/medium/ high density urban use, buildings, roads, and impervious surfaces (e.g., Buyantuyev and Wu 2010; Lo and Quattrochi 2003; Sun et al. 2012; Yuan and Bauer 2007; Zhou et al. 2011). Although many of these LULC variables have been found to significantly affect LST in urban areas, vegetation abundance and impervious surface area routinely emerge as the most important determinants. The strength of the relationships between LULC variables and LST, however, vary significantly from study to study due to the different measurement of variables and units of analyses (e.g., Huang et al. 2011; Li et al. 2012; Buyantuyev and Wu 2010; Yuan and Bauer 2007). For example, Yuan and Bauer (2007) found that although percent imperviousness was a strong predictor of the surface UHI throughout the year, the effects of vegetation phenology (as measured by NDVI) on LST result in relatively large seasonal variability. Similarly, Buyantuyev and $\mathrm{Wu}$ (2010) found diurnal variability in the relationships between LST and NDVI. Comparative analyses of different LULC variables as predictors of LST, however, are limited (Yuan and Bauer 2007; Li et al. 2011), and few studies have investigated the influence of the thematic (or categorical) resolution of LULC variables on the statistical relationship between LST and LULC.

Quantitative relationships between LST and LULC typically have been investigated with LULC data derived from low or medium resolution imagery, such as Landsat TM/ETM+ data (e.g., Weng et al. 2004; Yuan and Bauer 2007; Buyantuyev and Wu 2010), and ASTER images (e.g., Liu and Weng 2009). Imagery of high spatial resolution (e.g. IKONOS, QuickBird, Geoeye, and digital aerial image) and advances in image processing techniques render LULC data increasingly available at a very fine-scale (e.g., Zhou and Troy 2008; Lu et al. 2011). A few recent studies have examined relationships between LST and LULC variables derived from high spatial resolution imagery (e.g., Huang 2010; Zhou et al. 2011; Connors et al. 2012; Myint et al. 2013); however, few studies have investigated whether LULC variables derived from higher spatial resolution imagery are better predictors of LST and can better quantify the dynamics of surface UHIs.

We investigated the influence of spatial and thematic resolution of LULC data on the statistical relationships between LST and LULC variables in the 
Gwynns Falls watershed, Maryland, USA. Our objectives were to: (1) examine if an increase in the spatial resolution of LULC data could significantly increase the explanatory power of LULC variables on LST, (2) examine the relationship of LST to different LULC variables, and (3) investigate whether an increase in the thematic resolution of LULC data could significantly increase the explanatory power of LULC variables for LST. We also examined the seasonal variability of the effects of LULC variables on LST by using LST data acquired for four different seasons. We used three LULC datasets: (1) $0.6 \mathrm{~m}$ high spatial resolution land cover data derived from aerial imagery acquired in 1999; (2) 30 m NLCD 2001 datasets; and (3) NDVI data derived from the same Landsat-7 ETM+ images (but different bands) used for LST calculation. We developed multiple groups of models and compared them to evaluate effects of spatial and thematic resolution of LULC data on ability to predict LST from LULC variables. Results from our study can enhance understanding of interactions between urban surface characteristics and the spatial structure of urban thermal patterns (Voogt and Oke 2003). In addition, our research can provide important insights on selection of appropriate LULC data and variables for urban climate modeling.

\section{Methods}

Study area

Our study covered the Gwynns Falls watershed, the focal research watershed of the Baltimore ecosystem Study (BES), a long-term ecological research site (LTER) of the National Science Foundation (www. beslter.org). The watershed is approximately $171.5 \mathrm{~km}^{2}$, spanning Baltimore city and Baltimore county, Maryland, USA, and draining into the Chesapeake Bay (Fig. 1). The watershed traverses an urban-suburban-rural gradient, from the core of the city of Baltimore, through older, inner-ring suburbs, to rapidly suburbanizing areas in the middle reaches of the watershed, to the suburban-rural fringe in the headwaters region of the watershed. Land cover types are typical of those in urban and suburban environments, including commercial and industrial buildings, detached and multifamily houses, impervious surfaces such as asphalt roadways, concrete parking lots and sidewalks, and vegetation cover from trees, shrubs, and grass. Local climate is classified as humid subtropical, with average monthly temperature ranging from 1.7 to $26.7^{\circ} \mathrm{C}$ during winter and summer months, respectively, and average total precipitation of $1067 \mathrm{~mm}$ distributed evenly throughout the year (UMD 2001).

\section{Land surface temperature}

Seasonal LST data were derived from the thermal infrared (TIR) band (10.44-12.42 $\mu \mathrm{m})$ for four Landsat-7 ETM+ images (Row 33/Path 15) acquired on April 9, 2000; August 2, 2001; November 3, 2000; and February 5, 2000; to represent spring, summer, fall, and winter, respectively. These images were acquired at approximately 10:35am local time under clear atmospheric conditions. UHI surface temperatures generally are stronger and exhibit greater spatial variation during the daytime, in contrast to UHI air temperatures (Arnfield 2003; Nichol et al. 2009). UHI surface temperatures represented by image data collected in the mid-morning may differ from other periods of the day, including afternoon when temperatures are higher and may exhibit greater spatial variation. Therefore, the mid-morning daytime images are not ideal, but the satellite overpass schedule is fixed, and we expect thermal contrasts during midmorning to be sufficient for this study.

The four ETM+ images were obtained from the US geological survey (USGS) as Level-1 products, with radiometric and geometrical distortions corrected. The images were further rectified and georeferenced based on the 1999 aerial imagery (described in detail below) and was resampled using a nearest neighbor algorithm with a pixel size of $60 \mathrm{~m}$ for the thermal band. The root mean square (RMS) error was less than 0.30 pixels for each of the four images.

For each image, the digital number (DN) of the Landsat ETM+ high-gain TIR band first was converted to top-of-atmospheric (TOA) radiance using the formula provided by Landsat Project Science Office (2009):

$\mathrm{L}_{\lambda}=$ gain $\times \mathrm{DN}+$ offset

where "gain" is the rescaled gain (which equals to 0.03706 for the Landsat ETM+ high-gain TIR band) and "offset" refers to the rescale bias (value $=3.2$ ). 
Fig. 1 The Gwynns Falls watershed drains into the Chesapeake Bay. It includes portions of Baltimore City and Baltimore County, MD, USA

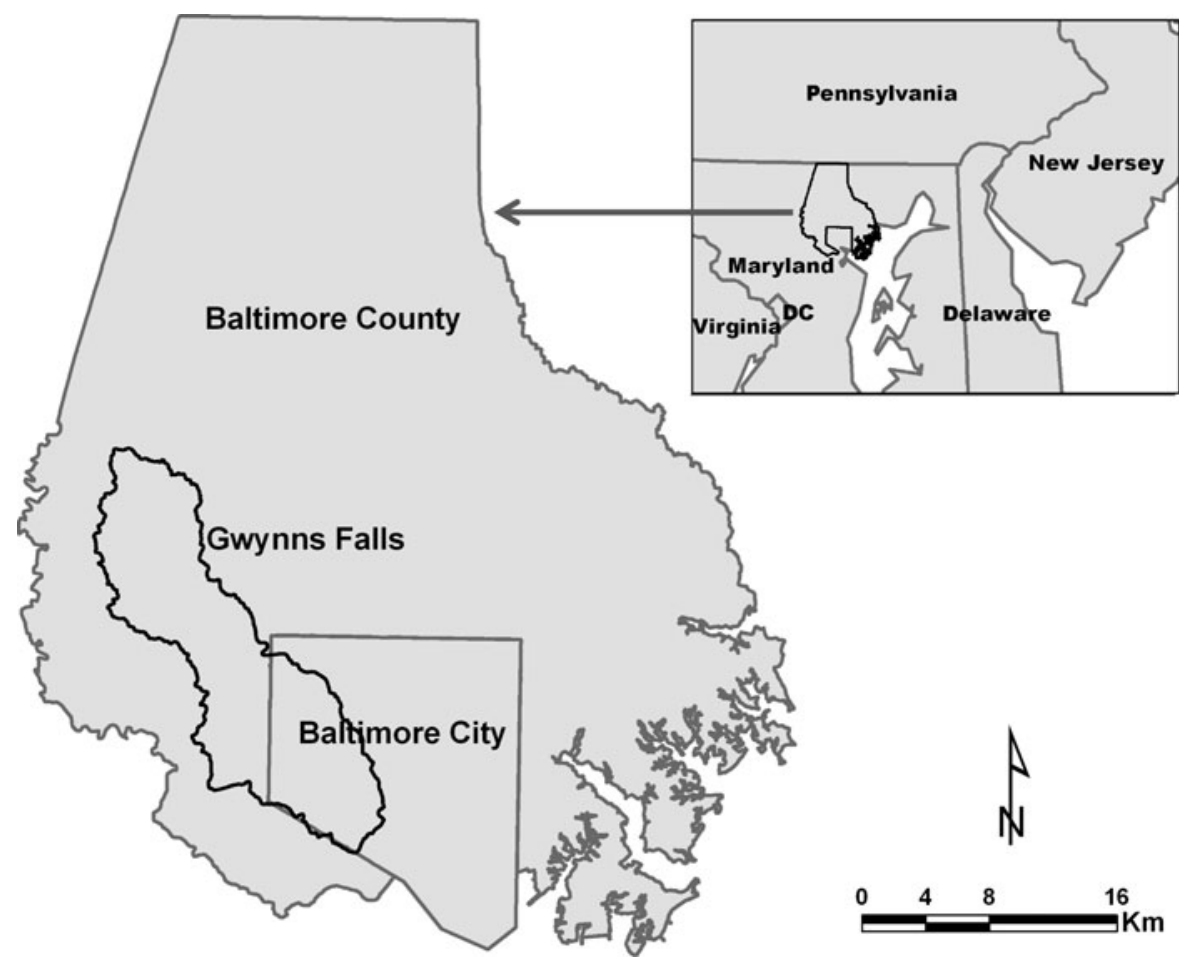

We then converted the TOA radiance to surfaceleaving radiance by removing the effects of atmosphere in the thermal region, using the equation below (Barsi et al. 2005; Yuan and Bauer 2007):

$\mathrm{L}_{\mathrm{T}}=\frac{\mathrm{L}_{\lambda}-\mathrm{L}_{\mu}-\tau(1-\varepsilon) \mathrm{L}_{\mathrm{d}}}{\tau \varepsilon}$

where $L_{T}$ is the surface leaving radiance of a blackbody target with kinetic temperature of $\mathrm{T}, \mathrm{L}_{\lambda}$ is the TOA radiance, $\mathrm{L}_{\mu}$ is the upwelling (or atmospheric path) radiance, $L_{d}$ is the downwelling (or sky) radiance, $\tau$ is the atmospheric transmission, and $\varepsilon$ is the emissivity of the surface. Radiances are in units of $\mathrm{W} \mathrm{m}{ }^{-2} \mathrm{sr}^{-1} \mu \mathrm{m}^{-1}$ and the transmission and emissivity are unitless. The atmospheric transmission and upwelling radiance and downwelling radiances were calculated using the web-based atmospheric correction tool (available at http://atmcorr.gsfc.nasa.gov/) developed by Barsi et al. (2005). The emissivity was estimated from the 2001 National Land Cover Datasets (NLCD), based on typical emissivities of different land cover types (Snyder et al. 1998; Lo and Quattrochi 2003).

Using the Landsat specific estimate of the Planck curve [Eq. (3)], the surface-leaving radiance was converted to apparent surface temperature (i.e., blackbody temperature):

$\mathrm{T}=\mathrm{K}_{2} / \ln \left(\mathrm{K}_{1} / \mathrm{L}_{\mathrm{T}}+1\right.$

where $\mathrm{T}$ is the apparent surface temperature in kelvin $(\mathrm{K}), \quad \mathrm{L}_{\mathrm{T}}$ is surface-leaving radiance in $\mathrm{W} \mathrm{m}{ }^{-2} \mathrm{sr}^{-1} \mu \mathrm{m}^{-1}$, and $\mathrm{K}_{2}$ and $\mathrm{K}_{1}$ are calibration constants with values equal to $1,282.71 \mathrm{~K}$ and $666.09 \mathrm{~W} \mathrm{~m}^{-2} \mathrm{sr}^{-1} \mu \mathrm{m}^{-1}$, respectively. With relatively clear atmosphere, the uncertainties of the apparent surface temperature are less than $2 \mathrm{~K}$ after the atmospheric correction (Barsi et al. 2005). Figure 2 shows the resultant image layer of apparent temperature (in kelvin) for each season.

\section{Land cover and NDVI data}

\section{High spatial resolution land cover data}

We used a land cover classification map of high spatial resolution (Zhou and Troy 2008) that contained six land cover types (Fig. 3): (1) trees and shrubs, (2) grass, (3) bare soil, (4) pavement, (5) buildings, and (6) water. The land cover classification was derived using an object-based classification approach from 
Fig. 2 LST derived from the Landsat ETM + imagery collected on four different dates for the Gwynns Falls watershed

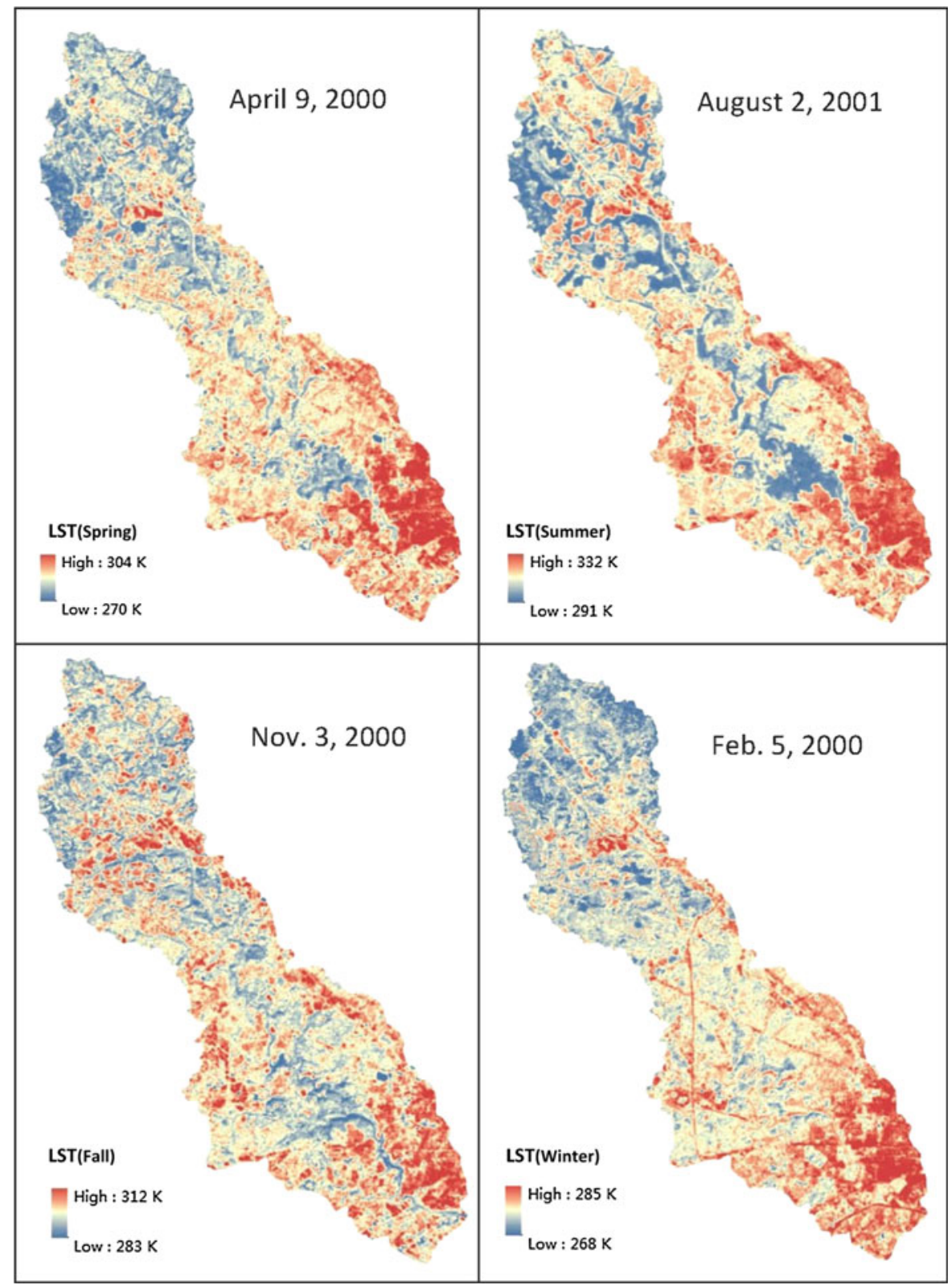

aerial imagery collected for the Gwynns falls watershed in October, 1999 (Zhou and Troy 2008). The imagery type was 3-band color-infrared (green: 510-600 nm, red: $600-700 \mathrm{~nm}$, and near-infrared: $800-900 \mathrm{~nm}$ ), with a pixel size of $0.6 \mathrm{~m}$. Overall accuracy of the classification was $92.3 \%$, with producer's accuracies ranging from 88.3 to $100 \%$ and user's accuracies ranging from 83.6 to $97.7 \%$ (Zhou and Troy 2008).
National Land Cover Data (NLCD 2001)

The continuous-field impervious surface and tree canopy density layers of the 2001 national land cover database (NLCD 2001) also were used for our study (Fig. 3). The NLCD 2001 products we used provided $30 \mathrm{~m}$ resolution data and were based on multitemporal Landsat-5 TM and Landsat-7 ETM+ imagery acquired from summer 1999 to spring 2001 for 
Fig. 3 A subset of the LST and each of the land cover dataset included in this analysis. a LST on August 2, 2001; b the aerial image collected in October, 1999; c the $0.6 \mathrm{~m}$ high spatial resolution land cover data-white: pavement, grey building, green grass, dark green trees and shrub, yellow bare soil; d NLCD percent impervious data-white is $0 \%$, dark red is $100 \%$; e NLCD percent canopy data-white is $0 \%$, dark green is $100 \%$; f NDVI data collected on August 2, 2001-the brighter, the higher value of NDVI. (Color figure online)
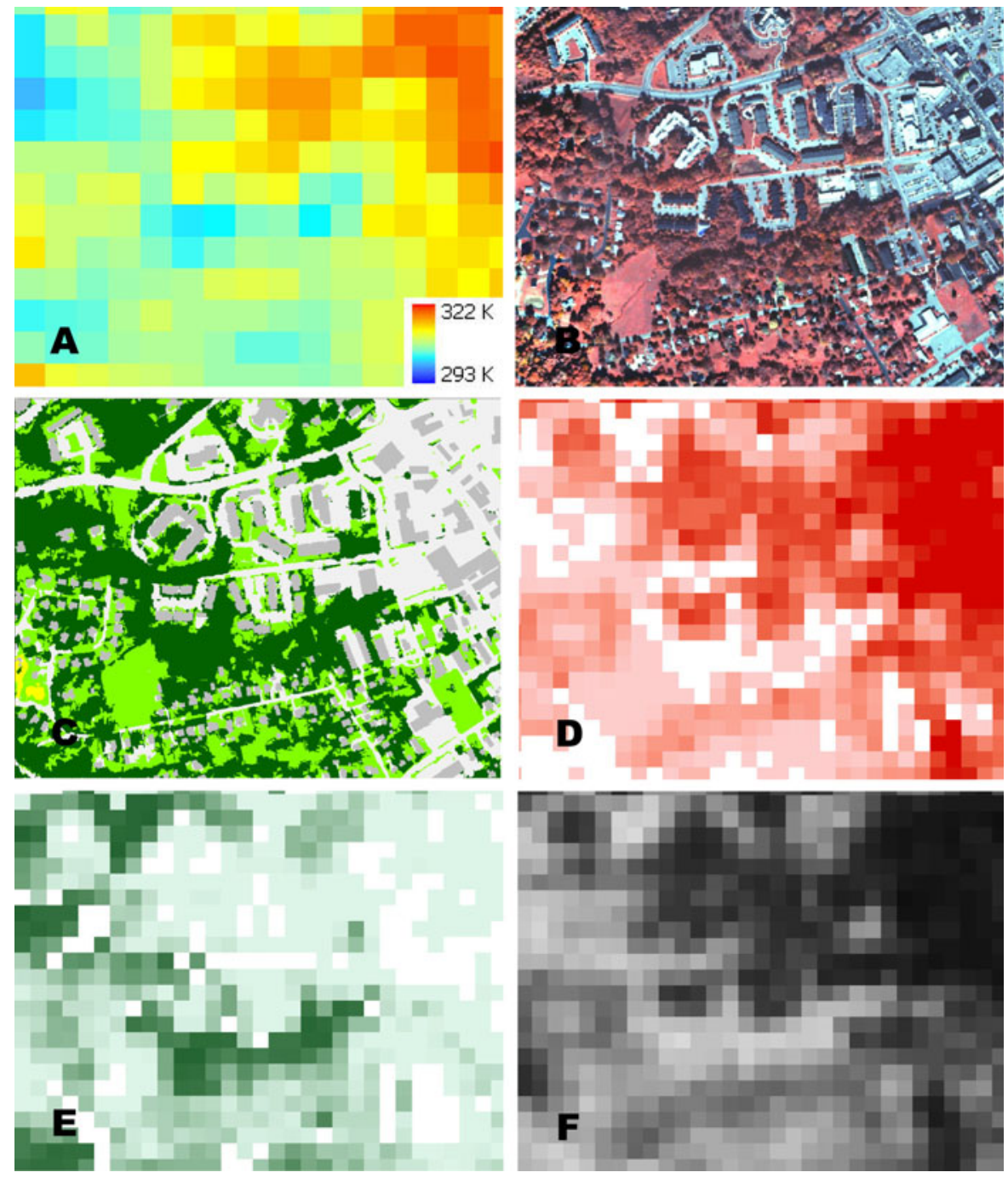

mapping zone 60, which encompassed our study area. Cross-validation results for mapping zone 60 reported correlation coefficients between predicted and actual values were 0.91 and 0.93 for imperviousness surface and tree canopy, respectively (Homer et al. 2004). The impervious surface and canopy density layers were used to calculate the percent of impervious cover (NLCDImper, Table 1) and the percent of tree canopy cover (NLCDCanopy, Table 1) for each unit of analysis as described below, respectively.

\section{Calculation of NDVI}

NDVI provides a measure of the abundance of actively photosynthesizing vegetation. It has been used frequently as an indicator of land surface characteristics in UHI studies (e.g., Buyantuyev and Wu 2010; Jenerette et al. 2007; Yuan and Bauer 2007). The value of NDVI ranges from -1 to 1 , but typically is between 0.1 and 0.7 for green vegetation, with higher index values indicating higher levels of healthy vegetation cover and higher density of vegetation. The NDVI data for each season were derived from the same Landsat ETM+ imagery as used for the LST calculation. The formula for NDVI is:

$\mathrm{NDVI}=(\mathrm{NIR}-\mathrm{RED}) /(\mathrm{NIR}+\mathrm{RED})$

where NIR is the reflectance in the near-infrared waveband (i.e., band 4) and RED is that of the visiblered waveband (i.e., band 3). 
Table 1 Summary of the LST and land cover variables

\begin{tabular}{|c|c|c|c|}
\hline Variable names & Description & Mean value & Std. Dev. \\
\hline \multicolumn{4}{|c|}{ Response variables, LST for four dates (Unit: K) } \\
\hline LSTSpring & The land surface temperature on April 9, 2000 & 289.96 & 2.12 \\
\hline LSTSummer & The land surface temperature on July 28, 1999 & 308.77 & 4.22 \\
\hline LSTFall & The land surface temperature on Nov. 1, 1999 & 297.08 & 1.50 \\
\hline LSTWinter & The land surface temperature on Feb. 5, 2000 & 274.35 & 1.41 \\
\hline \multicolumn{4}{|c|}{ Land cover predictors derived from high resolution land cover classification (\%) } \\
\hline PerBuild & Percent cover of buildings & 11.60 & 11.35 \\
\hline PerPave & Percent cover of paved surfaces & 34.45 & 25.11 \\
\hline PerTree & Percent cover of tree canopy & 28.38 & 18.36 \\
\hline PerGrass & Percent cover of herbaceous vegetation & 23.36 & 17.46 \\
\hline PerWater & Percent cover of water body & 0.18 & 1.27 \\
\hline PerBare & Percent cover of bare soil & 2.02 & 8.98 \\
\hline PerImper & $\begin{array}{l}\text { Percent cover of impervious surface, the sum of PerBuild } \\
\text { and PerPave; an aggregated variable }\end{array}$ & 34.97 & 25.57 \\
\hline PerVeg & $\begin{array}{l}\text { Percent cover of vegetation, the sum of PerTree } \\
\text { and PerGrass; an aggregated variable }\end{array}$ & 62.83 & 25.86 \\
\hline \multicolumn{4}{|c|}{ Land cover predictors derived from NLCD 2001} \\
\hline NLCDImper & $\begin{array}{l}\text { Percent cover of impervious surface obtained from } \\
\text { NLCD impervious layer }\end{array}$ & 26.08 & 23.79 \\
\hline NLCDCanopy & $\begin{array}{l}\text { Percent cover of tree canopy obtained from NLCD } \\
\text { tree canopy layer }\end{array}$ & 23.93 & 24.70 \\
\hline \multicolumn{4}{|c|}{ Normalized difference vegetation index (NDVI) derived from Landsat ETM + data } \\
\hline NDVISpring & Mean value of NDVI on April 9, 2000 & 0.02 & 0.13 \\
\hline NDVISummer & Mean value of NDVI on July 28, 1999 & 0.13 & 0.19 \\
\hline NDVIFall & Mean value of NDVI on Nov. 1, 1999 & 0.14 & 0.09 \\
\hline NDVIWinter & Mean value of NDVI on Feb. 5, 2000 & -0.16 & 0.03 \\
\hline
\end{tabular}

Statistical analyses

To minimize the potential effects of spatial autocorrelation, a sample of 500 randomly generated points was chosen from the study area to investigate the relationship between LST and land cover variables (Yuan and Bauer 2007; Buyantuyev and Wu 2010). The analytical unit of $3 \times 3$ pixels, or a grid cell of $180 \times 180 \mathrm{~m}^{2}$ was chosen to minimize the impacts of registration errors between the Landsat images and land cover layers (Yuan and Bauer 2007). Consequently, the mean LST was summarized for each analytical unit (i.e., a grid cell) and was used as the response variable for statistical analyses. The percent of each land cover type was also calculated for each grid cell for use as predictors. Table 1 lists the response and predictor variables.

\section{Model development}

We developed a Pearson correlation matrix to examine the strength of bivariate associations between the LST and the land cover variables (Table 2). We further used ordinary least squares (OLS) regressions to investigate the relationships between LST and the land cover variables. We developed ten models for each response variable (i.e., LST in each season): six models using land cover predictors derived from the high spatial resolution land cover classification data, three models using predictors from NLCD, and one model using NDVI (See Table 3). We used SPSS 16.0 for the Pearson correlation analyses and the development and comparisons of OLS models. 


\section{Model comparisons}

We applied multi-model inferential procedures (Burnham and Anderson 2002) for model comparisons. This approach is based on minimizing Akaike's Information Criterion (AIC) (Akaike 1978). We calculated an AIC value for each model. Two models were then compared based on the AIC values to determine the model that better balanced the model fit and model parsimony. The lower the value of AIC, the better a model. As a rule of thumb, one model is considered superior to the other if the difference of their AIC values is $<3$ (Akaike 1978; Burnham and Anderson 2002). We compared models to evaluate the effects of the spatial and thematic resolution of land cover data on understanding the relationship between LST and land cover for each season.

The effects of spatial resolution We compared models using the same descriptors of land cover surfaces (i.e. the same type of land cover classes), but which were derived from land cover classifications with different spatial resolution (i.e., the $0.6 \mathrm{~m}$ land cover classification map versus $30 \mathrm{~m}$ NLCD). For example, we compared model HTree, the one using percent cover of tree canopy derived from the $0.6 \mathrm{~m}$ land cover classification map (PerTree) as the predictor, with model LTree, the model using percent cover of tree canopy derived from the $30 \mathrm{~m}$ NLCD tree canopy layer (NLCDCanopy) (See Table 3). Similarly, we also compared model HImper with model LImper, and HTreeImper with LTreeImper.

The effects of thematic resolution To evaluate the effects of thematic (or categorical) resolution of land cover data on the relationships between LST and land cover, we compared some of the models in the model group that used predictors derived from the same land cover classification (See Table 4). More specifically, model HVeg was compared with model HTreeGrass to evaluate whether a further separation of vegetation into trees and grass could improve the explanatory power of the model. Similarly, HImper was compared with HBuildPave to evaluate the effects of a further separation of imperviousness into building and pavement. Model LNDVI was compared with models LTree and LImper to examine the explanatory power of NDVI versus percent cover of tree and imperviousness derived from the $30 \mathrm{~m} \mathrm{NLCD}$ land cover data. 
Table 3 Ten models that were developed and compared for each response variable (i.e., LST in each season)

\begin{tabular}{|c|c|c|}
\hline & Model names & Explanatory variables \\
\hline \multirow[t]{13}{*}{ Model Development } & \multicolumn{2}{|c|}{$\begin{array}{l}\text { Models using LULC predictors derived from high-spatial resolution } \\
\text { land cover data }\end{array}$} \\
\hline & HTree & PerTree \\
\hline & HImper & PerImper \\
\hline & HTreeImper & PerImper, PerTree \\
\hline & HVeg & PerVeg \\
\hline & HTreeGrass & PerTree, PerGrass \\
\hline & HBuildPave & PerBuild, PerPave \\
\hline & \multicolumn{2}{|c|}{ Models using LULC predictors derived from NLCD 2001} \\
\hline & LTree & NLCDCanopy \\
\hline & LImper & NLCDImper \\
\hline & LTreeImper & NLCDCanopy, NLCDImper \\
\hline & \multicolumn{2}{|l|}{ Model using NDVI as predictors } \\
\hline & LNDVI & NDVI of certain season \\
\hline \multirow[t]{8}{*}{ Model Comparisons } & \multirow{4}{*}{$\begin{array}{l}\text { Examine the effects of spatial } \\
\text { resolution }\end{array}$} & HTree versus LTree \\
\hline & & HImper versus LImper \\
\hline & & $\begin{array}{l}\text { HTreeImper versus } \\
\text { LTreeImper }\end{array}$ \\
\hline & & HFull versus LFull \\
\hline & \multirow{4}{*}{$\begin{array}{l}\text { Examine the effects of thematic } \\
\text { resolution }\end{array}$} & HVeg versus HTreeGrass \\
\hline & & HImper versus HBuildPave \\
\hline & & LNDVI versus LTree \\
\hline & & LNDVI versus LImper \\
\hline
\end{tabular}

Model comparisons were conducted to evaluate the effects of spatial and thematic resolution of land cover data on the relationship between LST and land cover, and to select the best model

\section{Results}

Bivariate associations between LST and land cover variables

The Pearson correlation coefficients show that most of the land cover variables derived from the highresolution land cover classification were significantly $(p<0.05)$ related to LST for all four seasons (Table 2). Percent cover of grass, water and bare soil were weakly related to LST, but other variables had relatively strong relationships with LST. Impervious surfaces, such as building roofs and pavement, had positive correlations with LST, and vegetation (including trees and grass), water, and bare soil, had negative correlations with LST, suggesting that an increase of imperviousness will increase LST, and increases in vegetated cover types will decrease LST (Appendix; Fig. A1-Supplementary data).

Percent imperviousness (NLCDImper) and tree canopy (NLCDCanopy) derived from NLCD were also significantly $(p<0.05)$ related to LST for all four seasons (Table 2). In particular, NLCDImper had a relatively strong relationship with LST for all four seasons (Appendix; Fig. A1-Supplementary data). NDVI also had a significant $(p<0.05)$ negative correlation with LST for all four seasons (Table 2; Appendix; Fig. A2-Supplementary data), with relatively strong relationships in summer and fall. Percent tree canopy derived from the high spatial resolution classification generally had a slightly stronger relationship with LST than that derived from NLCD throughout the year, but percent imperviousness derived from the high spatial resolution classification only had a slightly stronger relationship with LST for summer and fall data (Table 2).

Effects of land cover on LST: model comparisons

Effects of spatial resolution on understanding the relationship between LST and land cover

Our results showed that increased spatial resolution improved the explanatory power of land cover 
Table 4 Model comparisons to examine the effects of the spatial resolution of land cover data on understanding the relationships between LST and variables of land cover

\begin{tabular}{|c|c|c|c|c|c|c|c|c|c|c|}
\hline \multirow[t]{2}{*}{ Model comparison } & \multirow{2}{*}{$\begin{array}{l}\text { Model } \\
\text { name }\end{array}$} & \multirow[t]{2}{*}{ Predictors } & \multicolumn{4}{|c|}{ Adjusted R-squared } & \multicolumn{4}{|l|}{ AIC } \\
\hline & & & Spring & Summer & Fall & Winter & Spring & Summer & Fall & Winter \\
\hline \multirow{2}{*}{$\begin{array}{l}\text { Tree cover from data } \\
\text { with different } \\
\text { resolution }\end{array}$} & HTree & PerTree & 0.399 & 0.698 & 0.503 & 0.114 & 1963.9 & 2264.2 & 1476.1 & 1708.3 \\
\hline & LTree & NLCDCanopy & 0.387 & 0.624 & 0.436 & 0.092 & 1973.4 & 2374.9 & 1539.3 & 1720.5 \\
\hline \multirow{2}{*}{$\begin{array}{l}\text { Imperviousness from } \\
\text { data with different } \\
\text { resolution }\end{array}$} & HImper & PerImper & 0.621 & 0.779 & 0.54 & 0.504 & 1733.4 & 2108.8 & 1437.6 & 1418.6 \\
\hline & LImper & NLCDImper & 0.626 & 0.730 & 0.515 & 0.570 & 1726.3 & 2208.4 & 1464.6 & 1346.8 \\
\hline \multirow{2}{*}{$\begin{array}{l}\text { Tree cover and } \\
\text { imperviousness from } \\
\text { data with different } \\
\text { resolution }\end{array}$} & HTreeImper & $\begin{array}{l}\text { PerTree, } \\
\text { PerImper }\end{array}$ & 0.634 & 0.874 & 0.615 & 0.549 & 1717.2 & 1828.9 & 1349.1 & 1371.6 \\
\hline & LTreeImper & $\begin{array}{c}\text { NLCDCanopy, } \\
\text { NLCDImper }\end{array}$ & 0.661 & 0.853 & 0.599 & 0.601 & 1678.1 & 1906.8 & 1370.5 & 1310.5 \\
\hline
\end{tabular}

variables for some seasons (Table 4). The models using percent of tree cover (PerTree) derived from the $0.6 \mathrm{~m}$ classification map as the predictor were slightly better than the ones using tree canopy (NLCDCanopy) obtained from the $30 \mathrm{~m} \mathrm{NLCD}$ for all the four seasons (Table 4). The difference in the total variation of LST explained by the two variables (i.e., PerTree and NLCDCanopy) was small for every season. But the differences in AIC values between the models were often relatively large, suggesting the models using PerTree as the predictor were superior to those using NLCDCanopy (Table 4). Percent of imperviousness (PerImper) derived from the $0.6 \mathrm{~m}$ classification map was a better predictor than that from the $30 \mathrm{~m} \mathrm{NLCD}$ (NLCDImper) in summer and fall; but again, the difference in the total variation of LST explained by these two variables was small for each season (Table 4). Similarly, the models using predictors from $0.6 \mathrm{~m}$ classification map that included both percent cover of tree canopy and imperviousness were slightly better than those using variables from the $30 \mathrm{~m}$ NLCD for summer and fall (Table 4).

The spatial resolution of LULC data appears not to influence either the direction or magnitude of seasonal effects of percent of imperviousness and tree canopy on LST. For example, during summer, the standardized coefficient of 0.855 for percent of imperviousness (NLCDImper) derived from NLCD was very close to that of 0.883 for percent of imperviousness (PerImper) derived from the $0.6 \mathrm{~m}$ land cover data, suggesting percent of imperviousness derived from the two datasets had a very similar influence on predicting LST. Similarly, the standardized coefficient of -0.790 for NLCDCanopy was very close to that of -0.836 for PerTree.

Effects of thematic resolution on understanding the relationship between LST and land cover

Our results showed that increased thematic (or categorical) resolution of land cover generally enhanced the explanatory power of land cover on LST. For each of the four seasons, the model using both percent cover of trees (PerTree) and grass (PerGrass) as predictors was better than the model using only percent cover of vegetation (perVeg) (Table 5). While the difference in the total variation of LST explained between the models for each season was small, the differences in AIC values were relatively large, suggesting the models using both PerTree and PerGrass as predictors were superior to those using PerVeg alone (Table 5). The separation of impervious surfaces into building and pavement achieved slightly better prediction of LST for summer and fall. The differences in AIC values were close to 1 for spring and winter, which suggests that the two pairs of models are essentially equivalent (Table 5).

NDVI was the best predictor of LST for summer, which could explain approximately $88 \%$ of the variation of LST. But it could explain only about 26 and $12 \%$ of the total variation of LST in spring and winter, respectively (Table 5). Results listed in Table 4 also showed that adding more predictors generally led to better models. For example, a combination of percent of imperviousness and tree canopy could significantly better predict LST than 
Table 5 Model comparisons to examine the effects of the thematic resolution of land cover data on understanding the relationships between LST and variables of land cover

\begin{tabular}{|c|c|c|c|c|c|c|c|c|c|c|}
\hline \multirow[t]{2}{*}{ Model comparison } & \multirow{2}{*}{$\begin{array}{l}\text { Model } \\
\text { name }\end{array}$} & \multirow[t]{2}{*}{ Predictors } & \multicolumn{4}{|c|}{ Adjusted R-squared } & \multicolumn{4}{|l|}{ AIC } \\
\hline & & & Spring & Summer & Fall & Winter & Spring & Summer & Fall & Winter \\
\hline \multirow{2}{*}{$\begin{array}{l}\text { Vegetation versus } \\
\text { tree }+ \text { grass }\end{array}$} & HVeg & PerVeg & 0.541 & 0.778 & 0.524 & 0.421 & 1828.6 & 2111.7 & 1454.8 & 1495.3 \\
\hline & HTreeGrass & $\begin{array}{l}\text { PerTree, } \\
\text { PerGrass }\end{array}$ & 0.557 & 0.852 & 0.59 & 0.465 & 1812.0 & 1911.0 & 1381.2 & 1457.6 \\
\hline \multirow{2}{*}{$\begin{array}{l}\text { Imperviousness versus } \\
\text { building }+ \text { pavement }\end{array}$} & HImper & PerImper & 0.621 & 0.779 & 0.54 & 0.504 & 1733.4 & 2108.8 & 1437.6 & 1418.6 \\
\hline & HBuildPave & $\begin{array}{l}\text { PerBuild, } \\
\text { PerPave }\end{array}$ & 0.621 & 0.781 & 0.55 & 0.506 & 1734.3 & 2104.8 & 1427.3 & 1417.4 \\
\hline \multirow{2}{*}{$\begin{array}{l}\text { NDVI versus NLCD } \\
\text { tree canopy }\end{array}$} & LNDVI & NDVI & 0.261 & 0.885 & 0.304 & 0.123 & 2066.8 & 1783.9 & 1645.0 & 1703.3 \\
\hline & LTree & NLCDCanopy & 0.387 & 0.624 & 0.436 & 0.092 & 1973.4 & 2374.9 & 1539.3 & 1720.5 \\
\hline \multirow{2}{*}{$\begin{array}{l}\text { NDVI versus NLCD } \\
\text { imperviousness }\end{array}$} & LNDVI & NDVI & 0.261 & 0.885 & 0.304 & 0.123 & 2066.8 & 1783.9 & 1645.0 & 1703.3 \\
\hline & LImper & NLCDImper & 0.626 & 0.730 & 0.515 & 0.570 & 1726.3 & 2208.4 & 1464.6 & 1346.8 \\
\hline
\end{tabular}

using either variable (e.g. models HTreeImper versus HTree and HImper). This is true for datasets at two different resolutions for all four seasons. A combination of percent of imperviousness and tree canopy could explain substantially more total variation in LST than that using percent of tree canopy alone, but did not add much compared with models using percent of imperviousness only (Table 4). Nevertheless, models using a combination of percent of imperviousness and tree canopy were superior to those using percent of imperviousness alone, according to the AIC values.

\section{Discussion}

Effects of LULC variables on LST, and their seasonal variability

For all the LULC variables examined in this study, the direction of their effects (i.e., positive or negative) on LST were consistent across all seasons. However, the magnitude of their effects, as represented by their coefficient estimates in the models, exhibited seasonal variation. The coefficient estimates for most of the land cover predictors were larger in summer than for the other seasons and suggest urban land surfaces have larger impacts on LST during the summer. For example, an increase of $1 \%$ of vegetation cover would lead to a decrease of $0.144 \mathrm{~K}$ in LST during the summer time, but only $0.063 \mathrm{~K}$ in the spring, $0.042 \mathrm{~K}$ in the fall, and $0.036 \mathrm{~K}$ in the winter. As the ecological and social consequences of UHIs are the most significant in summer, the relatively high capacity of vegetation to reduce summer LST underscores the importance of increasing tree canopy for excessive heat mitigation. In addition, the strength of the association of LULC variables with LST also varied by season. The variation in LST can best be explained by LULC variables during summer, but the least during winter.

Impervious surface has a significantly positive effect on LST. Percent of imperviousness is the best predictor of LST for all four seasons among all the LULC variables examined in this study, except for summer. In addition, the explanatory power of this variable on LST is relatively consistent across seasons. Percent of imperviousness, alone, can explain approximately $50 \%$ of the total variation in LST in winter time, and up to $77.9 \%$ during summer. Therefore, percent of imperviousness can be a very useful predictor for surface UHI modeling. These results are consistent with previous findings (Yuan and Bauer 2007).

Vegetation has a significantly negative effect on LST. Vegetation related variables, including percent of tree canopy, percent of vegetation, and NDVI, are important predictors for LST. For example, percent of tree canopy alone could explain approximately $69 \%$ of the total variation in LST for summer. However, in contrast to impervious surfaces, the effects of vegetation related variables on LST varied largely by season. In general, vegetation related variables were good predictors of LST during summer and fall, but not during spring and winter. In particular, percent of 
tree canopy and NDVI could only explain approximately $10 \%$ of the total variation in LST in winter. Similar results were found in the much colder Twin Cities Metropolitan Area of Minnesota (Yuan and Bauer 2007) and in the much hotter and drier Phoenix metropolitan region of Arizona (Buyantuyev and $\mathrm{Wu}$ 2010; Jenerette et al. 2011).

This relatively large season variability in the relationships of percent of tree canopy and NDVI to LST may be largely due to the seasonal variability in climatic conditions in Baltimore, and the distribution of deciduous vegetation within the study area. Shedding of leaves from deciduous trees in winter greatly reduces canopy evapotranspiration (latent heat flux), and thus reduces the capacity of trees in regulating surface temperature due to latent heat exchange. In addition, the cooler air temperatures in winter also would greatly reduce the evapotranspiration of plants. In fact, the NDVI values in winter were almost entirely less than 0 (Appendix; Fig. A2-Supplementary data), which indicated there was very little actively photosynthesizing vegetation during this period. Consequently, plants play a much less important role in regulating LST during winter, and variation in LST mostly is related to non-vegetated surfaces (i.e., impervious surfaces) in urban areas in that season (Yuan and Bauer 2007). This explains a much lower negative correlation between vegetation related variables and LST in winter for the Twin cities metropolitan area of Minnesota (Yuan and Bauer 2007), as well as for Baltimore, Maryland, our study area.

In addition, the scatter plots of residuals versus vegetation related predictors indicated potential "funneling effects" (i.e., residuals are spread out for small $\mathrm{x}$ values and close to 0 for large $\mathrm{x}$ values), suggesting unequal variation (i.e., heteroscedasticity) in residuals (e.g., Appendix; Fig. A3-Supplementary data, first graph in the left column). We log transformed the data, but this did not appear to improve the model. Therefore, these results may suggest that using vegetation related variables alone as predictors might be not appropriate for some seasons, and a different specification of the model is needed (Appendix; Fig. A3-Supplementary data). For example, percent cover of tree canopy and NDVI were poor predictors of LST in winter. Nevertheless, percent cover of tree canopy can be used as a complementary metric to percent cover of imperviousness for analysis on LST over the seasons for surface UHI studies. For all the four seasons, a combination of tree canopy and imperviousness significantly improved prediction of LST over imperviousness, alone. It is also worth noting that NDVI in summer better predicted LST in the other three seasons than NDVI from the corresponding season (results not included in the tables). These results may suggest that NDVI data acquired in summer shall be used when using NDVI to predict LST in different seasons.

Effects of spatial resolution on understanding the relationship between LST and land cover

Our results indicate that the increase of spatial resolution did not necessarily improve the explanatory power of land cover variables. The effects of spatial resolution varied by land cover variables. In general, percent cover of tree canopy derived from the higher resolution land cover data was a better predictor than that derived from the $30 \mathrm{~m} \mathrm{NLCD}$. The effects of increased spatial resolution on percent cover of impervious surfaces, however, varied by season. In addition, with the two land cover datasets, the difference in the total variation of LST explained by these two variables (i.e., percent cover of tree canopy and impervious surfaces), or their combination, is small.

These results were surprising as a number of studies suggest that percent cover of imperviousness and tree canopy generally are underestimated by the NLCD impervious surface and tree canopy layers, particularly in urban settings (e.g., Zhou and Troy 2009; Greenfield et al. 2009; Nowak and Greenfield 2010; Smith et al. 2010). This also is true for our study area (Smith et al. 2010). Our results indicated this underestimation might not affect our understanding on the relationships between LST and these two variables. This may be because the underestimation of the percent cover of impervious surfaces and tree canopy in the NLCD dataset is a systematic error, and therefore while the absolute values are different between the two datasets, the relative values remain similar across the different levels of cover. In fact, a previous study showed very strong linear relationships between percent impervious surface cover and percent tree canopy cover derived from the high resolution classification versus those derived from the $30 \mathrm{~m}$ NLCD (Smith et al. 2010).

A variety of remotely sensed data of different spatial resolutions can be used to quantify the spatial 
heterogeneity of land cover. Spatial resolution (or grain size) of image data affects the results of land cover mapping and spatial pattern analysis (Wu 2004; Shao and Wu 2008; Alhamad et al. 2011) and, in turn, the understanding of the relationships between land cover and LST. Therefore, it is critical to identify the range of spatial resolutions at which relationships between LST and land cover can best be characterized (Shao and Wu 2008). Our results for these relationships were robust across the two scales of land cover data we analyzed. The very similar results we obtained with percent tree canopy and impervious surfaces with different spatial resolution data suggests that the nationally available (and free of cost) $30 \mathrm{~m}$ NLCD impervious surface and tree canopy layers can be as effective for surface UHI modeling at the landscape scale as data of higher spatial resolution that are substantially more limited in availability.

However, we shall note that these results were obtained when the spatial resolution of LST data was much coarser than that of the land cover data. The spatial resolution of LST data used in this study was $60 \mathrm{~m}$ (the finest spatial resolution that currently can be obtained from satellite image), close to the $30 \mathrm{~m}$ resolution of the NLCD data, but much coarser than the $0.6 \mathrm{~m}$ of the fine resolution land cover data. It would be interesting to examine whether using thermal data from a higher-resolution would yield different results. This shall be further investigated in future research. Therefore, we note that interpretation of the results from this analysis should be couched in terms of the spatial resolution of the thermal data relative to that of the land cover data. In addition, it would be interesting to examine whether and how the size of the analytical unit may affect the observed relationships between LST and land cover variables in future research.

Effects of thematic resolution on understanding relationships between LST and LULC

Increase of thematic resolution generally enhances the explanatory power of LULC on LST, but not to a substantial degree. For example, the classification of impervious surfaces into buildings and pavement could improve the explanatory power of land cover on LST. Similarly, the separation of vegetation into trees and grass could achieve better prediction on LST. The amount of the increase in variation explained, however, was not substantial, generally less than $5 \%$, when increasing the thematic resolution. Therefore, it may be reasonable to use the aggregated land cover classes (e.g., impervious surface versus building and pavement), since they are usually more readily available.

In this study, we did not separate the vegetation into deciduous versus evergreen. It would be interesting to investigate whether such separation could improve the explanatory power of the models, particularly for winter and spring.

Limitations and suggested future research

This study has its limitations. Both land cover datasets were obtained using images acquired in growing seasons. The static land cover data that were used to predict seasonal LST could not well represent the seasonal changes in land cover. For example, snow cover in winter and lacks of crops in the fields during early to mid-spring were not reflected from the static land cover maps, which potentially might contribute to the seasonal variability in explanatory power of the land cover variables. It is also important to note that while the accuracies of the land cover datasets were relatively high, errors in either land cover datasets may impact the results from the analyses (Lechner et al. 2012). We did not explicitly address this issue in this study. It would be very interesting to evaluate how mapping errors may impact the understanding of the relationships between LST and land cover variables. In addition, we note the current analysis was conducted for only one metropolitan area in one type of climatic zones, and recommend cross-site evaluation for future research to help explore the consistency of observed relationships.

\section{Summary and conclusions}

We investigated seasonal variability in the use of land cover variables and spatial and thematic resolutions of land cover data on estimating LST. We found that for all the land cover variables we examined the directions of their effects on predicting LST were consistent across seasons. The magnitude of their effects varied largely by season. Percent of imperviousness is the best predictor on LST with consistent explanatory power across seasons, accounting for the majority of 
the variation in LST. Percent of tree canopy is an important predictor for LST during spring through fall, and can be a useful complement to percent of impervious surfaces for analysis of LST for surface UHI studies. Our results indicated relationships between NDVI and LST have relatively large seasonal variability, and that NDVI is a useful predictor for LST during summer and fall, but not for spring and winter in a subtropical city.

We found the spatial resolution of land cover data may not significantly affect the relationships between LST and land cover variables where the LST data is at a coarser scale. Land cover variables derived from the $0.6 \mathrm{~m}$ resolution land cover data have similar explanatory power on LST as those derived from the $30 \mathrm{~m}$ NLCD. Therefore, the NLCD 2001 data can be a useful data source for surface UHI studies of US cities, particularly for large region or cross-site comparisons. This is encouraging because NLCD data are freely available and provide national coverage. We found increasing thematic resolution of land cover data can enhance the explanatory power of land cover on LST, though not substantially.

Our results and conclusions were based on LST data from only one daytime thermal image for each of the four seasons from a single thermal sensor type, and the research was conducted for only one metropolitan area. Future comparison studies across metropolitan areas under different climatic conditions and, perhaps, for additional thermal sensors, is desirable to confirm and refine these findings.

Acknowledgments The support of the State Key Laboratory of Urban and Regional Ecology, Research Center for EcoEnvironmental Sciences, Chinese Academy of Sciences, is gratefully acknowledged. This research also was supported by the National Science Foundation LTER program (DEB 042376). The authors would like to thank the editor and the anonymous reviewers for their helpful comments and suggestions. Comments from Dr. Brian Voigt improved the early draft of this manuscript.

\section{References}

Akaike H (1978) On the likelihood of a time series model. Stat 27:217-235

Akbari H, Pomerantz M, Taha H (2001) Cool surfaces and shade trees to reduce energy use and improve air quality in urban areas. Sol Energy J 70:295-310
Alhamad MN, Alrababah MA, Feagin RA, Gharaibeh A (2011) Mediterranean drylands: the effect of grain size and domain of scale on landscape metrics. Ecol Indic 11:611-621

Arnfield AJ (2003) Two decades of urban climate research: a review of turbulence, exchanges of energy and water, and the urban heat island. Int J Climatol 23:1-26

Balling RC, Brazel SW (1988) High resolution surface temperature pattern in a complex urban terrain. Photogramm Eng Remote Sens 54:1289-1293

Barsi JA, Schott JR, Palluconi FD, Hook SJ (2005). Validation of a web-based atmospheric correction tool for single thermal band instruments. Earth observing systems X. In: Proceedings of SPIE Vol. 5882, San Diego, CA

Ben-Dor E, Saaroni H (1997) Airborne video thermal radiometry as a tool for monitoring microscale structures of the urban heat island. Int J Remote Sens 18(4):3039-3053

Burnham KP, Anderson DR (2002) Model selection and multimodel inference: a practical information-theoretic approach. Springer, New York

Buyantuyev A, Wu J (2010) Urban heat islands and landscape heterogeneity: linking spatiotemporal variations in surface temperatures to land-cover and socioeconomic patterns. Landscape Ecol 25(1):17-33

Connors JP, Galletti CS, Chow WTL (2012) Landscape configuration and urban heat island effects: assessing the relationship between landscape characteristics and land surface temperature in Phoenix, Arizona. Landscape Ecol. doi:10.1007/s10980-012-9833-1

Duneier M (2006) Ethnography, the ecological fallacy, and the 1995 Chicago heat wave. Am Sociol Rev 71:679-688

Greenfield EJ, Nowak DJ, Walton J (2009) Assessment of 2001 NLCD percent tree and impervious cover estimates. Photogram Eng Remote Sens 75(11):1279-1286

Guhathakurta S, Gober P (2007) The impact of the Phoenix urban heat island on residential water use. J Am Plan Assoc 73:317-329

Homer C, Huang C, Yang L, Wylie B, Coan M (2004) Development of a 2001 National Land Cover Database for the United States. Photogram Eng Remote Sens 70(7):829-840

Huang GW, Zhou, Cadenasso ML (2010) Understanding the relationship between urban land surface temperature, landscape heterogeneity and social structure. In: Proceedings of the 2010 IEEE international geoscience and remote sensing symposium, 3933-3936

Huang G, Zhou W, Cadenasso ML (2011) Is everyone hot is the city? Spatial pattern of land surface temperatures, land cover and neighborhood socioeconomic characteristics in Baltimore city, MD. J Environ Manag 92(7):1753-1759

Jenerette GD, Harlan SL, Brazel A, Jones N, Larsen L, Stefanov WL (2007) Regional relationships between surface temperature, vegetation, and human settlement in a rapidly urbanizing ecosystem. Landscape Ecol 22:353-365

Jenerette GD, Harlan SL, Stefanov WL, Martin CA (2011) Ecosystem services and urban heat riskscape moderation: water, green spaces, and social inequality in Phoenix, USA. Ecol Appl 21:2637-2651

Klinenberg E (2002) Heat Wave: a social autopsy of disaster in Chicago. University of Chicago Press, Chicago

Landsat Project Science Office. Landsat 7 Science Data Users Handbook (2009). Available via http://landsathandbook. gsfc.nasa.gov/handbook.html. Accessed on 22 Oct 2010 
Lechner AM, Langford WT, Bekessy SA, Jones SD (2012) Are landscape ecologists addressing uncertainty in their remote sensing data? Landscape Ecol 27(9):1249-1261

Li J, Song C, Cao L, Zhu F, Meng X, Wu J (2011) Impacts of landscape structure on surface urban heat islands: a case study of Shanghai, China. Remote Sens Environ 115: 3249-3263

Li X, Zhou W, Ouyang Z, Xu W, Zheng H (2012) Spatial pattern of greenspace affects land surface temperature: evidence from the heavily urbanized Beijing metropolitan area, China. Landscape Ecol 27:887-898

Liu H, Weng Q (2009) Scaling-up effect on the relationship between landscape pattern and land surface temperature. Photogram Eng Remote Sens 75(3):291-304

Lo CP, Quattrochi DA (2003) Land-use and land-cover change, urban heat island phenomenon, and health implications: a remote sensing approach. Photogram Eng Remote Sens 69(9):1053-1063

Lu D, Hetricka S, Morana E (2011) Impervious surface mapping with quickbird imagery. Int J Remote Sens 32(9):2519-2533

Myint S, Wentz E, Brazel A, Quatrochi D (2013) The impact of distinct anthropogenic and vegetation features on urban warming. Landscape Ecol 28:959-978

Nichol JE (1994) A GIS-based approach to microclimate monitoring in Singapore's high-rise housing estates. Photogram Eng Remote Sens 60:1225-1232

Nichol JE (1996) High-resolution surface temperature patterns related to urban morphology in a tropical city: a satellitebased study. J Appl Meteorol 35:135-146

Nichol JE (1998) Visualisation of urban surface temperatures derived from satellite images. Int J Remote Sens 19(9): 1639-1649

Nichol JE, Fung WY, Lam K, Wong MS (2009) Urban heat island diagnosis using ASTER satellite images and 'in situ' air temperature. Atmos Res 94(2):276-284

Nowak DJ, Greenfield EJ (2010) Evaluating the national land cover database tree canopy and impervious cover estimates across the conterminous United States: a comparison with photo-interpreted estimates. Environ Manag 46:378-390

Oke TR (1995) The heat island of the urban boundary layer: characteristics, causes and effects. In: Cermak JE (ed) Wind climate in cities. Kluwer Academic Publishers, Netherlands, pp 81-107

Pu R, Gong P, Michishita R, Sasagawa T (2006) Assessment of multi-resolution and multi-sensor data for urban surface temperature retrieval. Remote Sens Environ 104:211-225
Quattrochi DA, Luvall JC (1999) Thermal infrared remote sensing for analysis of landscape ecological processes: methods and applications. Landscape Ecol 14:577-598

Shao G, Wu J (2008) On the accuracy of landscape pattern analysis using remote sensing data. Landscape Ecol 23: 505-511

Smith MA, Zhou W, Cadenasso M, Grove M, Band L (2010) Evaluation of the national land cover database for hydrologic applications in urban and suburban Baltimore Maryland. J Am Water Resour Assoc 46(2):429-442

Snyder W, Wan Z, Zhang Y, Feng Y, Feng Z (1998) Classification-based emissivity for land surface temperature measurement from space. Int J Remote Sens 19:2753-2774

Sun RH, Chen AL, Chen LD, Lü YH (2012) Cooling effects of wetlands in an urban region: the case of Beijing. Ecol Indic 20:57-64

University of Maryland (UMD) (2001) Normal precipitation and temperature values for Baltimore city from 1961 to 1990. Baltimore, Maryland

Voogt JA, Oke TR (2003) Thermal remote sensing of urban climates. Remote Sens Environ 86:370-384

Weng Q, Lu D, Schubring J (2004) Estimation of land surface temperature-vegetation abundance relationship for urban heat island studies. Remote Sens Environ 89:467-483

White MA, Nemani RR, Thornton PE, Running SW (2002) Satellite evidence of phenological differences between urbanized and rural areas of the eastern United States deciduous broadleaf forest. Ecosystems 5:260-277

Wu J (2004) Effects of changing scale on landscape pattern analysis: scaling relationships. Landscape Ecol 19:125-138

Yuan F, Bauer ME (2007) Comparison of impervious surface area and normalized difference vegetation index as indicators of surface urban heat island effects in Landsat imagery. Remote Sens Environ 106:375-386

Zhou W, Troy A (2008) An object-oriented approach for analyzing and characterizing Urban landscape at the parcel level. Int J Remote Sens 29:3119-3135

Zhou W, Troy A (2009) Development of an object-based framework for classifying and inventorying human-dominated forest ecosystems. Int J Remote Sens 30(23): 6343-6360

Zhou W, Huang G, Cadenasso ML (2011) Does spatial configuration matter? Understanding the effects of land cover pattern on land surface temperature in urban landscapes. Landscape Urban Plan 102(1):54-63 